\title{
A Study of the Awareness Levels of Universal Precautions in High-risk Areas of a Super-specialty Tertiary Care Hospital
}

\author{
${ }^{1}$ Amit Lathwal, ${ }^{2}$ Sanjay Kumar Arya, ${ }^{3}$ IB Singh, ${ }^{4}$ Ravinder Ahlawat, ${ }^{5}$ Kanika Jain
}

\begin{abstract}
Centers for disease control and prevention (CDC), Atlanta, in 1987, defined universal precautions and recommended that blood and body fluid precautions be consistently used for all patients. Although universal precautions have been in existence for a long period of time and the risk of transmission of blood borne infections to healthcare workers (HCWs) is very real, the awareness levels among HCWs to these precautions is still far from satisfactory.

This study was conceived to study the knowledge of universal precautions in high-risk areas of a super-specialty tertiary care hospital in India among different categories of HCWs.

A pretested structured questionnaire common to all the categories of HCWs was used to study the awareness levels of universal precautions. Each question was assigned a unit score. Seventy-five percent score in the questionnaire was taken as cut-off for adequate knowledge.

The findings of the study reveal that the HCWs who had adequate knowledge of universal precautions were $29(30 \%)$ out of $96 \mathrm{HCWs}$. These included $17(53 \%)$ doctors, $8(36 \%)$ nurses, $3(31 \%)$ technical staffs and $1(5 \%)$ housekeeping staff.

Keywords: Blood-borne infections, Healthcare workers, Tertiary care hospital, Universal precautions.
\end{abstract}

How to cite this article: Lathwal A, Arya SK, Singh IB, AhlawatR, Jain K. A Study of the Awareness Levels of Universal Precautions in High-risk Areas of a Super-specialty Tertiary Care Hospital. Int J Res Foundation Hosp Healthc Adm 2015;3(2):98-102.

\section{Source of support: Nil}

Conflict of interest: None

\section{INTRODUCTION}

All healthcare workers (HCWs) and patients in healthcare settings are at a considerable risk to acquire various bloodborne infections, especially human immunodeficiency virus (HIV), hepatitis B virus (HBV), and hepatitis $\mathrm{C}$

\footnotetext{
${ }^{1}$ Assistant Professor, ${ }^{2,3}$ Professor, ${ }^{4,5}$ Senior Resident

${ }^{1-5}$ Department of Hospital Administration, All India Institute of Medical Sciences, New Delhi, India
}

Corresponding Author: Amit Lathwal, Assistant Professor Department of Hospital Administration, All India Institute of Medical Sciences, New Delhi, India, e-mail: amit.lathwal@ yahoo.co.in virus (HCV). These patients can neither be recognized on physical appearance nor on physical examination. These potentially fatal infections have no cure and no vaccine (except hepatitis B) and the cornerstone of prevention in healthcare settings is the simple practice of universal precautions. Universal precautions have been defined by centers for disease control and prevention (CDC) Atlanta, ${ }^{1}$ and these are basic protective measures to prevent parentral, mucous membrane and non-intact skin exposure of HCW to blood borne pathogens. Implementation of universal precautions will reassure both HCWs and patients attending hospitals regarding reduced risk of accidental transmission of blood-borne pathogens.

\section{AIM}

The aim of the study was to study the awareness levels of universal precautions in high-risk areas of a superspecialty tertiary care hospital at New Delhi in India.

\section{METHODOLOGY}

This study was conceived to study the awareness levels of universal precautions in high-risk areas of a superspecialty tertiary care hospital in India among four categories of HCWs viz doctors, nurses, technical staffs and housekeeping staffs. The study is descriptive and cross-sectional in nature. High-risk areas were those departments or wards where probability of exposure to blood and body fluids is higher due to either increased handling or large number of interventions performed and thus, six areas were selected which were blood bank, main laboratory, main operation theatre (OT), main intensive care unit (ICU), emergency services and dialysis unit.

Questionnaire was used to study the awareness level of universal precautions among the different categories of HCWs. A common questionnaire was prepared in bilingual language for all categories of HCWs. The questionnaire was prepared after extensive review of literature and discussions with hospital administrators. The questionnaire consisted of three segments:

Part I consisted of questions 1 to 6 and these were related to demographic data. 
Part II consisted of questions 7 to 15 and these were used to assess the knowledge of various components of universal precautions.

Part III consisted of questions 16 to 25 which were related to practice of various components of universal precautions.

\section{ANALYSIS OF QUESTIONNAIRE}

Questions from 7 to 25, which pertained to knowledge and practice of universal precautions, were included in the scoring system. Each of these questions was assigned a unit score. Thus, the score could vary from 0 to 19 . Maximum score of 19 would mean that responses for all 19 questions were correct representing the level of awareness as $100 \%$. Seventy-five percent was taken as a cut-off for adequate knowledge, i.e. those HCWs who answered $75 \%$ or more questions correctly were considered to have adequate knowledge ${ }^{2}$ of universal precautions and others (i.e. those with less than $75 \%$ correct responses) were considered to be having inadequate knowledge. The questionnaire was pretested through a pilot study done on $12 \mathrm{HCWs}$, three from each category. The questionnaires were distributed to each HCW personally. The requisite information and explanations were also provided wherever required. The participants were expected to complete the questionnaires according to their convenience and return them back within 7 days. If they were not returned within 7 days, the participants were reminded to complete the questionnaire and return it. The study population of different categories of HCWs in the six areas of the study was $255+126+101+87=$ 569. Out of these $32+22+21+21=96(16.87 \%)$ HCWs were selected by simple random sampling to assess the awareness levels of universal precautions through the questionnaire.

\section{RESULTS AND DISCUSSION}

There were a total of 96 HCWs who participated in the study to assess the awareness levels of universal precautions. These comprised of 32 doctors, 22 nurses, 21 technical staffs and 21 housekeeping staffs. Out of the 96 HCWs, 67 (69.79\%) were males and 29 (30.21\%) females. The reason for male preponderance is that majority of HCWs in technical staff and housekeeping staff working are males. Eighty-one ( $84.38 \%$ ) of HCWs were in the age group of 20 to 40 years and 15 (15.63\%) were in the age group of 41 to 60 years. Fifty-eight $(60.42 \%)$ had 0 to 10 years of service and $38(39.58 \%)$ had more than 10 years of service. Out of 32 doctors, 9 were graduates and 23 were postgraduates; of the 22 nurses, 1 was MSc, 5 were BSc and the remaining 16 were diploma holders; of the 21 technical staffs, 10 were graduates, 6 were senior secondary and the remaining 5 were matriculates; of the 21 housekeeping staffs, 3 were postgraduates, 2 were senior secondary, 11 were matriculates and the remaining 5 were below matriculates. Of the 96 HCWs, 12 (12.5\%) were from the blood bank which included 2 doctors, 2 nurses, 5 technical staffs and 3 housekeeping staffs, $14(14.6 \%)$ were from the main lab which include 3 doctors, 7 technical staffs and 4 housekeeping staffs, 20 (20.8\%) were from the main OT which included 9 doctors, 4 nurses, 3 technical staffs and 4 housekeeping staffs, 17 (17.7\%) were from the main ICU which included 8 doctors, 4 nurses, 2 technical staffs and 3 housekeeping staffs, $25(26.1 \%)$ were from the emergency services which include 8 doctors, 10 nurses, 2 technical staffs and 5 housekeeping staffs, $8(8.3 \%)$ were from the dialysis unit which included 2 doctors, 2 nurses, 2 technical staffs and 2 housekeeping staffs. The findings of the study are as under.

The study population of different categories of HCWs was $255+126+101+87=569$, and out of these $32+22+$ $21+21=96(16.87 \%)$ HCWs were selected to assess the awareness levels of universal precautions through the questionnaire.

The awareness level of universal precautions was determined by a questionnaire consisting of 25 questions out of which first six related to demographic profile and the remaining 19 (7th to 25th) questions were used to check awareness levels. One hundred and four questionnaires were distributed out of which 96 were returned, thus leading to a response rate of $92.31 \%$.

There were 6 questions out of 19 in which overall (combination of all the 4 groups of HCWs) more than $40 \%$ of HCWs answered these wrongly. These being question no. 13, 16, 17, 18, 21, and 22. For question no. 13th which was 'universal precautions apply to which body fluids?', only a dismal 10 (10.42\%) respondents gave correct answers. For question no. 16th which was 'when should hand washing be performed by HCWs?' only 57 (59.38\%) respondents gave correct answers. For question no. 17th which was 'what should be done if hands are soiled with blood or body fluids?' only 45 (46.88\%) respondents gave correct answers. For question no. 21st which was that 'in which conditions should HCWs refrain from all direct patient care activities?' only $37(38.54 \%)$ respondents gave corrects answers. For question no. 22nd which was 'what precautions should be taken during the management of HIV patient?' only $47(48.96 \%)$ respondents gave correct answer. From the above observation, it is clear that in some areas of the universal precautions the awareness levels among the HCWs was low. These being as under: - To which blood and body fluids universal precautions apply?

- When should HCWs perform hand washing? 
- When should gloves be worn by the HCWs?

- What should HCWs do if their hands are soiled with blood or body fluids?

- In which conditions should HCWs refrain from all direct patient care activities?

- What precautions should be taken during the management of HIV patient?

Some of the above mentioned are key components of Universal precautions, thus it can be concluded that knowledge gaps exist among the HCWs and awareness levels among them needs to be improved.

Tables 1 to 3 reveal that the overall mean correct answer score by all the 4 categories of HCWs was 13.1 (68.9\%) out of the 19 questions or $100 \%$ score. The correct answer score among the doctors was 14.5 (76.3\%), among the nurse was $13.5(71.1 \%)$, among the technical staff was $12.2(64.2 \%)$ and among the housekeeping staff was
$11.3(59.5 \%)$. The difference among the four groups of HCWs was statistically significant $(\mathrm{p}<0.001)$ (Graph 1$)$.

The study findings reveal that the highest awareness levels were among the doctors as compared to nurses, technical staff and housekeeping staff suggesting that higher qualification has a positive impact on awareness of Universal precautions.

Vij et $\mathrm{al}^{3}$ in a study in 1999 at Main Hospital of All India Institute of Medical Sciences, New Delhi to assess the knowledge of staff nurses on infection control measures concluded that the mean knowledge of staff nurses regarding infection control measures was $73.1 \%$. The findings in the present study are comparable to these.

Another study by Clement et $\mathrm{al}^{4}$ conducted on all surgical trainees in Nigeria in 1997 to determine the knowledge, attitude and risk perception of Nigerian surgery residents to HIV infection and AIDS showed

Table 1: Existing and the selected population of health care workers from each study unit

\begin{tabular}{|c|c|c|c|c|c|c|c|c|}
\hline \multirow[b]{2}{*}{ Study unit } & \multicolumn{2}{|c|}{ Doctors } & \multicolumn{2}{|c|}{ Nurses } & \multicolumn{2}{|c|}{ Technical staffs } & \multicolumn{2}{|c|}{ Housekeeping staffs } \\
\hline & $E(N)$ & $S(n)$ & $E(N)$ & $S(n)$ & $E(N)$ & $S(n)$ & $E(N)$ & $S(n)$ \\
\hline Blood bank & 4 & 2 & 2 & 2 & 22 & 5 & 7 & 3 \\
\hline Main laboratory & 12 & 3 & 0 & 0 & 46 & 7 & 17 & 4 \\
\hline Gyne OT & 48 & 5 & 5 & 2 & 2 & 2 & 6 & 2 \\
\hline Surgery OT & 38 & 4 & 8 & 2 & 2 & 1 & 4 & 2 \\
\hline Total main OT & 86 & 9 & 13 & 4 & 4 & 3 & 10 & 4 \\
\hline Main ICU & 60 & 8 & 35 & 4 & 12 & 2 & 12 & 3 \\
\hline Emergency services & 77 & 8 & 69 & 10 & 10 & 2 & 35 & 5 \\
\hline Dialysis unit & 16 & 2 & 7 & 2 & 7 & 2 & 6 & 2 \\
\hline Total & 255 & 32 & 126 & 22 & 101 & 21 & 87 & 21 \\
\hline
\end{tabular}

E: Existing population in the study units; S: selected sample of HCWs for the study

Table 2: Correct responses of questions 7 to 25 by different categories of HCWs

\begin{tabular}{|c|c|c|c|c|c|c|c|c|c|}
\hline \multirow[b]{2}{*}{ Q. No. } & \multicolumn{2}{|c|}{$\begin{array}{l}\text { Doctors } \\
(N=32)\end{array}$} & \multicolumn{2}{|c|}{$\begin{array}{l}\text { Nurses } \\
(N=22)\end{array}$} & \multicolumn{2}{|c|}{$\begin{array}{c}\text { Technical staff } \\
(N=21)\end{array}$} & \multicolumn{2}{|c|}{$\begin{array}{l}\text { Housekeeping staff } \\
(N=21)\end{array}$} & \multirow[b]{2}{*}{$p$-value } \\
\hline & $N$ & $\%$ & $N$ & $\%$ & $N$ & $\%$ & $N$ & $\%$ & \\
\hline 7 & 30 & 93.75 & 22 & 100 & 21 & 100 & 21 & 100 & 0.25 \\
\hline 8 & 32 & 100 & 22 & 100 & 14 & 66.67 & 16 & 76.19 & 0.001 \\
\hline 9 & 32 & 100 & 17 & 77.27 & 17 & 80.95 & 11 & 52.38 & 0.001 \\
\hline 10 & 25 & 78.13 & 17 & 77.27 & 11 & 52.38 & 7 & 33.33 & 0.003 \\
\hline 11 & 30 & 93.75 & 19 & 86.36 & 21 & 100 & 19 & 90.48 & 0.36 \\
\hline 12 & 29 & 90.63 & 18 & 81.82 & 14 & 66.67 & 16 & 76.19 & 0.18 \\
\hline 13 & 6 & 18.75 & 4 & 18.18 & 0 & 0 & 0 & 0 & 0.03 \\
\hline 14 & 32 & 100 & 21 & 95.5 & 21 & 100 & 21 & 100 & 0.33 \\
\hline 15 & 26 & 81.25 & 13 & 59.09 & 17 & 80.95 & 15 & 71.43 & 0.26 \\
\hline 16 & 18 & 56.25 & 11 & 50 & 11 & 52.38 & 17 & 80.95 & 0.14 \\
\hline 17 & 17 & 53.13 & 19 & 86.36 & 8 & 38.10 & 10 & 47.62 & 0.009 \\
\hline 18 & 21 & 63.63 & 11 & 50 & 7 & 33.33 & 6 & 28.57 & 0.03 \\
\hline 19 & 31 & 96.88 & 18 & 81.82 & 14 & 66.67 & 17 & 80.95 & 0.03 \\
\hline 20 & 22 & 68.75 & 17 & 77.27 & 12 & 57.14 & 9 & 42.86 & 0.09 \\
\hline 21 & 17 & 53.13 & 8 & 36.36 & 7 & 33.33 & 5 & 23.81 & 0.16 \\
\hline 22 & 23 & 71.88 & 13 & 59.09 & 8 & 38.10 & 3 & 14.29 & 0.001 \\
\hline 23 & 27 & 84.38 & 16 & 72.73 & 17 & 80.95 & 16 & 76.19 & 0.74 \\
\hline 24 & 25 & 78.13 & 16 & 72.73 & 15 & 71.43 & 17 & 80.95 & 0.86 \\
\hline 25 & 21 & 65.63 & 15 & 68.18 & 21 & 100 & 11 & 52.38 & 0.006 \\
\hline
\end{tabular}

$\mathrm{N}$ : Total no. of HCWs in the category selected for the study; $\mathrm{n}$ : Number of HCWs whose responses were correct; $p<0.05$ : Significant and is depicted in bold 
Table 3: Mean scores of correct answers by HCWs in different study units

\begin{tabular}{|c|c|c|c|c|c|c|}
\hline \multirow[b]{2}{*}{ Study unit } & \multicolumn{4}{|c|}{ Mean score of HCWs (0-19) } & \multirow[b]{2}{*}{ Total } & \multirow[b]{2}{*}{$p$-value } \\
\hline & Doctors & Nurses & Technical staff & Housekeeping staff & & \\
\hline Blood bank & $16(84.2)$ & $15.5(81.6)$ & $12(63.2)$ & $9.7(51.1)$ & $12.7(66.8)$ & 0.01 \\
\hline Main laboratory & $15(78.9)$ & - & $11.7(61.6)$ & $9.5(50)$ & $11.8(62.1)$ & 0.14 \\
\hline Main OT & $13.7(72.1)$ & $12(63.2)$ & $11.7(61.6)$ & $11.5(60.5)$ & $12.6(66.3)$ & 0.16 \\
\hline Main ICU & $14.5(76.3)$ & $13(68.4)$ & $13.5(71.1)$ & $13.3(70)$ & $13.8(72.6)$ & 0.31 \\
\hline Emergency services & $14.8(77.9)$ & $14.1(74.2)$ & $10.5(55.3)$ & $12.2(64.2)$ & $13.6(71.6)$ & 0.09 \\
\hline Dialysis unit & $15(78.9)$ & $12.5(65.8)$ & $15.5(81.6)$ & $11.5(60.5)$ & $13.6(71.6)$ & 0.38 \\
\hline Total & $14.5(76.3)$ & $13.5(71.1)$ & $12.2(64.2)$ & $11.3(59.5)$ & $13.1(68.9)$ & 0.001 \\
\hline$p$-value & 0.28 & 0.41 & 0.07 & 0.09 & 0.19 & \\
\hline
\end{tabular}

Mean score range from 0 to 19 ; Figures in parenthesis indicate percentage; $p<0.05$ : Significant and is depicted in bold

that $44.2 \%$ of the respondents knew the CDC guidelines for universal precautions well, $44.0 \%$ had an idea of these guidelines, i.e. knew them partially and $13.8 \%$ had no idea about them.

Among the different study units, the mean correct answer scores were $12.7(66.8 \%)$ in the blood bank, 11.8 $(62.1 \%)$ in the main laboratory, $12.6(66.3 \%)$ in the main OT, $13.8(72.6 \%)$ in the main ICU and $13.6(71.6 \%)$ in the emergency services and the dialysis unit (Graph 2).

The above findings reveal that the awareness levels in the main ICU, emergency services and the dialysis unit were better in comparison to blood bank, main lab and the main OT, thus indicating that these areas need greater educational and training interventions.

Table 4 reveals the number and percentages of HCWs who answered more than $75 \%$ questions in the questionnaire correctly, i.e. those who can be considered as having adequate knowledge $(75 \%$ score was taken as cut-off score for adequate knowledge of universal precautions). ${ }^{2}$

Overall 29 HCWs out of 96 , i.e. $30 \%$ answered more than $75 \%$ questions in the questionnaire correctly. Those

Table 4: Healthcare workers in different study units who scored $75 \%$ or more questions correctly, i.e. who had adequate knowledge

\begin{tabular}{lllllll}
\hline & \multicolumn{5}{c}{ Healthcare workers } & \\
\cline { 2 - 5 } & Doctors & Nurses & Technical staff & Housekeeping staff & Total \\
Study unit & $(N=32)$ & $(N=22)$ & $(N=21)$ & $n / N(\%)$ & $n / N(\%)$ & $p$-value \\
\hline Blood bank & $n / N(\%)$ & $n / N(\%)$ & $n / N(\%)$ & $0 / 3(0)$ & $3 / 12(25)$ & $\mathbf{0 . 0 2}$ \\
Main laboratory & $2 / 2(100)$ & $1 / 2(50)$ & $0 / 5(0)$ & $0 / 4(0)$ & $2 / 14(14)$ & $\mathbf{0 . 0 1}$ \\
Main OT & $2 / 3(67)$ & - & $0 / 7(0)$ & $0 / 4(0)$ & $3 / 20(15)$ & 0.59 \\
Main ICU & $2 / 9(22)$ & $1 / 4(25)$ & $0 / 3(0)$ & $0 / 3(0)$ & $7 / 17(41)$ & 0.25 \\
Emergency services & $5 / 8(63)$ & $1 / 4(25)$ & $1 / 2(50)$ & $0 / 5(0)$ & $10 / 25(40)$ & 0.08 \\
Dialysis unit & $5 / 8(63)$ & $5 / 10(50)$ & $0 / 2(0)$ & $1 / 2(50)$ & $4 / 8(50)$ & 0.26 \\
\hline Total & $1 / 2(50)$ & $0 / 2(0)$ & $2 / 2(100)$ & $1 / 21(5)$ & $29 / 96(30)$ & $\mathbf{0 . 0 0 1}$ \\
\hline
\end{tabular}

$\mathrm{N}$ : Total number of HCWs; $\mathrm{n}$ : HCWs who have scored $75 \%$ or more questions correctly; Figures in parenthesis indicate percentage $p<0.05$ : Significant and is depicted in bold

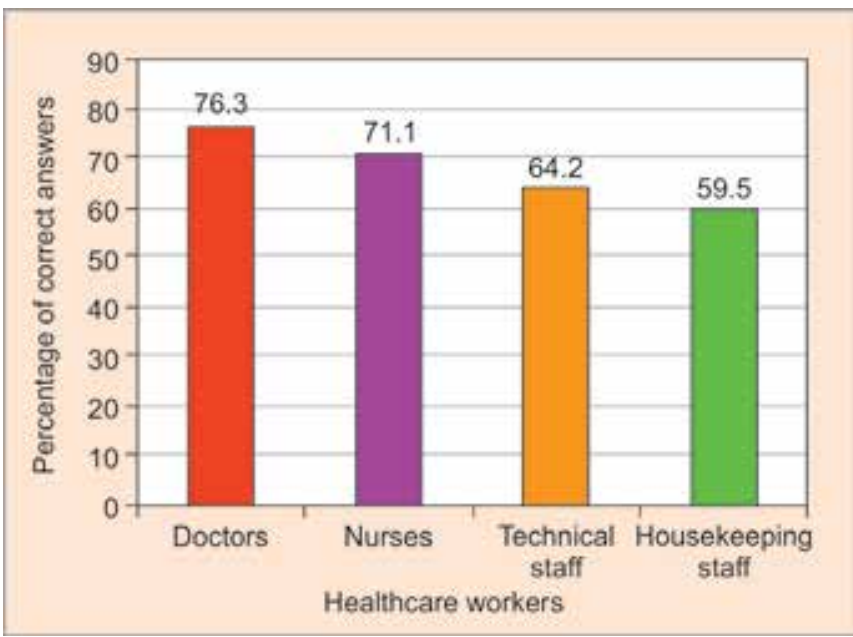

Graph 1: Mean percentage of correct answers by the four categories of HCWs

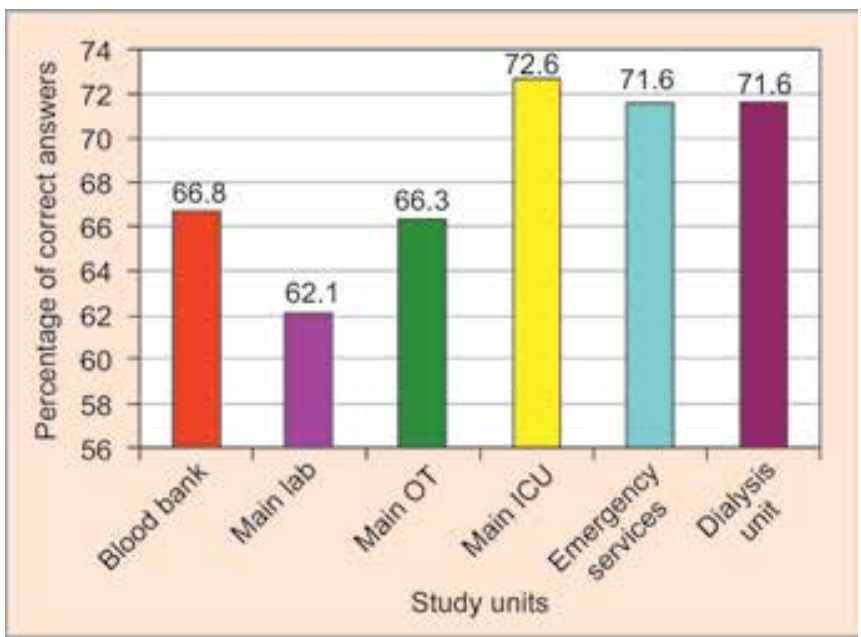

Graph 2: Mean percentage of correct answers by HCWs in the six study units 
who answered more $75 \%$ questions correctly were $17(53 \%)$ among the doctors, $8(36 \%)$ among the nurses, $3(31 \%)$ among the technical staff and $1(5 \%)$ in the housekeeping staff. The difference among the four groups was statistically significant $(\mathrm{p}<0.001)$.

The study findings again reveal that the highest awareness levels were among the doctors as compared to nurses, technical staff and housekeeping staff suggesting that higher qualification has a positive impact on awareness of universal precautions.

Among the different study units, the percentage of HCWs who answered more than $75 \%$ questions correctly were $25 \%$ in the blood bank, $14 \%$ in the main laboratory, $15 \%$ in the main OT, $41 \%$ in the main ICU, $40 \%$ in the emergency services and $50 \%$ in the dialysis unit.

The above findings reveal that the awareness levels in the dialysis unit were satisfactory but were very low in blood bank, main lab and the main OT, thus indicating that these areas need educational and training interventions.

The findings also reveal that educational and training interventions are required for doctors of main OT and dialysis unit, nurses of all the six study units, technical staff of all the units except dialysis unit and housekeeping staff of all the six study units.

In a study by Gumodoko et $\mathrm{al}^{2}$ conducted in nine hospitals in Mwanza region of Tanzania in 1997 showed that $65 \%$ of the HCWs had inadequate knowledge of the occupational risks of HIV transmission. Half of the medical staff and over $90 \%$ of the nursing attendants had inadequate knowledge. The findings are comparable with the present study which shows that $70 \%$ of HCWs had inadequate knowledge.

\section{CONCLUSION}

Although universal precautions have been in existence for a long time and the risk of transmission of bloodborne infections to HCWs is very real, the awareness levels to universal precautions are far from satisfactory and need improvements particularly among nurses, technical staff and housekeeping staff. The awareness levels among doctors though satisfactory but still needs some improvements. It is the responsibility of the hospital authorities and administrators toward the hospital, through trainings, supervision and stricter enforcement and of the HCWs toward themselves and their patients, through awareness and compliance to ensure that these precautions are actually implemented.

\section{REFERENCES}

1. Centers for disease control and prevention. Recommendations for Prevention of HIV Transmission in Healthcare Settings. MMWR 1987;36(SU02):1-17.

2. Gumodoka B, Favot I, Berege ZA, Dolomans WMV. Occupational exposure to the risk of HIV infection among healthcare workers in Mwanza region, United Republic of Tanzania; Bulletin of the WHO 1997;75(2):133-140.

3. Vij A, Williamson SN, Gupta S. Knowledge and practices of nursing staff towards infection control measures in a tertiary care hospital. J Acad Hospital Adminis 2001 July-Dec;13(2):31-35.

4. Available at: www.biomedcentral.com. 